\title{
On the mechanism of exfoliation of 'Vermiculite'
}

\author{
S. HILLIER ${ }^{1,2, *}$, E. M. M. MARWA ${ }^{3,4}$ And C. M. RICE ${ }^{3}$ \\ ${ }^{1}$ The James Hutton Institute, Craigiebuckler, Aberdeen, AB15 8QH, UK, ${ }^{2}$ Department of Soil and Environment, \\ Swedish University of Agricultural Sciences (SLU), P.O. Box 7014, SE-750 07 Uppsala, Sweden, ${ }^{3}$ Department of \\ Geology and Petroleum Geology, University of Aberdeen, AB24 3UE, UK, and ${ }^{4}$ Sokoine University of Agriculture, \\ Department of Soil Science, P. O. Box 3008, Morogoro, Tanzania
}

(Received 20 May 2013; revised 27 July 2013; Editor: George Christidis)

\begin{abstract}
Six samples of 'Vermiculite' have been studied to investigate the mechanism of its well known but poorly understood property to exfoliate. The samples were analysed quantitatively by XRD to determine their precise mineralogical composition. Electron microprobe methods, including elemental mapping of native potassium and of caesium (introduced by cation exchange) were used to examine variation in the chemical composition of the particles. Most of the samples examined show heterogeneous mineralogical compositions which occur as distinct zones within the volume of individual particles, presenting a mosaic texture. Exfoliation is related to this mosaic distribution of the different mineral phases within the particles. Lateral phase boundaries between vermiculite and mica layers, or vermiculite and chlorite layers are postulated to prevent or impede the escape of gas from a particle, resulting in exfoliation when the pressure exceeds the interlayer bonding forces that hold the layers together. This mechanism provides a common explanation for the exfoliation of 'Vermiculite' by thermal methods or by treatment with $\mathrm{H}_{2} \mathrm{O}_{2}$. Paradoxically, one sample which consists of pure vermiculite, in the mineralogical sense of the term, demonstrates that pure vermiculite does not and should not exhibit the property of exfoliation. Our explanation of the mechanism of exfoliation explains the commonly observed particle size dependence of exfoliation and the tendency for obviously poly-phase 'Vermiculite' samples to show the largest coefficients of expansion.
\end{abstract}

Keywords: vermiculite, hydrobiotite, phlogopite, exfoliation, hydrogen peroxide.

As a traded commodity, the term 'Vermiculite' is used to describe commercially exploited deposits of micaceous minerals which can be exfoliated when heated rapidly to high temperatures (Hindman, 2006). Exfoliation involves a volume expansion with individual platy particles expanding perpendicular to the cleavage planes, bloating in an accordion- or concertina-like fashion to up to 20-30 times their original volume (Walker, 1951). In their exfoliated form, the accordions of

* E-mail: stephen.hillier@hutton.ac.uk DOI: 10.1180/claymin.2013.048.4.01 vermiculite are often curved, which together with their segmented appearance evokes the vermiform resemblance to worms, and explains the origin of the name 'vermiculite'. Historically, any mineral that showed the property of exfoliation when flashheated was identified as 'vermiculite' (Walker, 1951). Even in the earliest literature it was, however, known that other minerals, in particular hydrobiotites, also exhibited the property of exfoliation when heated rapidly. The term hydrobiotite was reintroduced by Gruner (1934) in his classic study of vermiculites to denote minerals that he correctly identified as intimate interstratifications of mica and vermiculite layers. In fact, it later became established that hydrobiotites often showed 
a greater propensity to exfoliate compared with true vermiculites. Thus, Midgley \& Midgley (1960) examined sixteen commercial vermiculites, finding that none were pure true vermiculites. They observed that the largest degree of exfoliation was associated with the occurrence of hydrobiotite and the lowest degree of exfoliation with the occurrence of true vermiculite. Indeed of the eleven specimens of vermiculite examined originally by Gruner (1934) only three (Nos. 8, 9 and 10) were listed as 'easily' or 'readily' exfoliating and all three were designated as hydrobiotites, all containing appreciable alkalis, mainly potassium, in obvious contrast to the specimens designated as true vermiculite in which alkalis were essentially absent. It should be noted, however, that Gruner (1934) did not comment at the time on any relationship of mineralogy to exfoliation. Subsequently, in a classic French study Couderc \& Douillet (1973) examined a further thirty one specimens of commercial vermiculites, with samples from thirteen localities spread across nine different countries. Only two specimens, both from Brazil, appeared to be pure true vermiculite and these showed by far the lowest coefficients of expansion. The remaining specimens were identified as various mixtures of vermiculite, interstratified mica/vermiculite types and mica. Despite analysing 31 specimens, Couderc \& Douillet (1973) failed to establish a detailed relationship between exfoliation and the mineralogical composition of their specimens, noting only that samples showing regular interstratification of mica and vermiculite layers (hydrobiotite), as the dominant phase showed the highest coefficients of expansion. More recently, Justo et al. (1989) confirmed these observations, finding much higher coefficients of expansion for two hydrobiotitedominated samples, compared to four samples of pure vermiculite.

In the mineralogical, as opposed to the commercial commodity sense, vermiculite is a precisely defined name for a group of $2: 1$ phyllosilicates with a layer charge of between 0.6 and 0.9 per $\mathrm{O}_{10}(\mathrm{OH})_{2}$ formula unit (Bailey, 1980; Guggenheim et al., 2006). On this basis vermiculites are distinguished from smectites with lower layer charge and micas which usually have higher values. X-ray diffraction (XRD) patterns of vermiculites have first-order basal spacings of between about 14 and $15 \AA$ and if homo-ionic and pure (in the sense of having no interstratification with other phases such as mica) they show a series of higher order basal peaks that are rational on the primary basal spacing (Brindley \& Brown, 1984; de la Calle \& Suquet, 1988). Vermiculites may be dioctahedral or trioctahedral although it appears that all known macroscopic occurrences (Foster, 1961; Douglas, 1989) and certainly all commercially exploited deposits (Hindman, 2006) are trioctahedral.

By far the most well known method of exfoliating vermiculite is by short lived rapid so called 'shock' or 'flash' heating. Commercially, this is usually achieved by heating to temperatures of around $900^{\circ} \mathrm{C}$ for a few minutes or more in a vertical or rotary furnace (Hindman, 2006). With some vermiculites in the laboratory the onset of exfoliation can be observed at temperatures as low as $300^{\circ} \mathrm{C}$, although rapid heating at $100^{\circ} \mathrm{C}$, a temperature at which around half of the interlayer water in vermiculite is lost, does not result in exfoliation (Walker, 1951). Interestingly, other authors have indicated that the temperature of the onset of thermal exfoliation can also be lowered by cation exchange treatments with $\mathrm{Na}^{+}$, or $\mathrm{NH}_{4}^{+}$ (Muiambo et al., 2010; Huo et al., 2012). The experiments of Muiambo et al. (2010) were conducted on specimens of the well known Palabora vermiculite from Phalaborwa, South Africa, whilst the specimen examined by Huo et al. (2012) from China was described as an industrial ("interstratified") vermiculite. Microwaves have also been employed successfully by several investigators as an alternative thermal method to exfoliate vermiculite (e.g. Obut et al., 2003; Marcos \& Rodríguez, 2011).

As well as thermal methods, vermiculite may also be exfoliated chemically. By far the most effective chemical method known is that of using hydrogen peroxide $\left(\mathrm{H}_{2} \mathrm{O}_{2}\right)$. The exfoliating action of $\mathrm{H}_{2} \mathrm{O}_{2}$ on particles of weathered mica was first noted independently by Drosdoff \& Miles (1938) and Groves (1939) during soil particle size analyses procedures where $\mathrm{H}_{2} \mathrm{O}_{2}$ was used to oxidize organic matter. Drosdoff \& Miles (1938) tested 20 museum specimens of vermiculite and whilst most showed no reaction at all, two samples of 'philadephite' (a defunct varietal name for hydrobiotite) exfoliated readily. Groves (1939) provided no details of the vermiculite specimens he examined but speculated that the exfoliation effect observed upon the action of $\mathrm{H}_{2} \mathrm{O}_{2}$ was possibly due to the evolution of oxygen between the flakes, although he noted that this did not provide explanation for the observed 
'asymmetric expansion and the zones of different colour'. More recently, Üçgül \& Girgin (2002) and Obut \& Girgin (2002) investigated the effects of $\mathrm{H}_{2} \mathrm{O}_{2}$ on a phlogopite from Turkey. The potassium content of this material is in fact far too low for a pure phlogopite and XRD evidence presented in Üçgül \& Girgin (2002) is suggestive of some interstratification with vermiculite. Another chemical method that produces exfoliation is treatment with sulphuric acid. Ruthruff (1941) noted that hydrobiotite exfoliated greatly when soaked in concentrated sulfuric acid for $48 \mathrm{~h}$ and then spread out and allowed to dry in air, whereas true vermiculite similarly treated showed no exfoliation. Walker (1951) later commented that this might be used as a test to distinguish between the two minerals. Exfoliation by sulfuric acid was explained by Ruthruff (1941) as due to displacive growth of sulfates between the layers. Üçgül \& Girgin (2002) also tested exfoliation of the Turkish phlogopite with $\mathrm{H}_{2} \mathrm{SO}_{4}, \mathrm{HCl}, \mathrm{HNO}_{3}$ and $\mathrm{H}_{3} \mathrm{PO}_{4}$ but in contrast to $\mathrm{H}_{2} \mathrm{O}_{2}$ no response was noted.

In general, the mechanism of thermal exfoliation of vermiculite is ascribed by most workers to the rapid production of steam during flash-heating which forces open the layers of vermiculite as the steam escapes from the structure. Nonetheless, commenting on exfoliation in her review of thermally modified clay minerals, Heller-Kallai (2006) concluded that "no completely satisfactory explanation for the unique behaviour of vermiculite has yet been offered". It is also unclear if the phenomenon of thermal exfoliation has mechanistic factors in common with chemical exfoliation. In terms of the basic mechanism of exfoliation there are three main pertinent observations, and it is useful to review these before we progress. Firstly, many authors have pointed out that thermal exfoliation only occurs when the particles of vermiculite are flash-heated; in contrast slow heating does not result in exfoliation. Secondly, exfoliation is often noted to be a function of particle size. Smaller particles sizes typically show less expansion compared to larger particle sizes. And thirdly, interstratified mica/vermiculite invariable shows a greater propensity to exfoliate compared to samples of pure vermiculite. As such, most commercial vermiculites typically contain large proportions of hydrobiotite rather than true vermiculite. Any proposed mechanism for exfoliation should be able to explain all three of these observations.
Walker (1951) also pointed out the early confusion that occurred in nomenclature because of the variability of the mineralogy of 'vermiculite' over small distances. On the smallest scale this is exemplified by single particles that may consist of zones of mica, zones of true vermiculite and zones of interstratification of the two. On larger scales, heterogeneity is represented by samples of 'vermiculite' that are variable mixtures of different minerals (e.g. vermiculite, hydrobiotite and phlogopite), resulting in the potential for substantial differences in mineralogical composition and behaviour between specimens from the same locality. No doubt if insufficient attention is given to the characterisation of vermiculites the results reported may serve to cloud our understanding of the mechanism of exfoliation. Indeed, Frank \& Edmond (2001), although mainly concerned with identification of asbestos in vermiculite, are at pains to point out that it is difficult to compare much of the data in the literature because vermiculites and hydrobiotites have so often been grouped together as 'vermiculites' in many studies, especially those that address commercial aspects. In fact, returning to the classic work of Walker (1951) it can be noted that he saw fit to comment that of the eleven specimens that he originally examined eight turned out to be hydrobiotite.

Even though there have been many studies of vermiculite it is clear that a completely satisfactory explanation for the mechanism of exfoliation has not yet been offered. There is also a growing and active interest in exfoliation not only of clay minerals but of a wide variety of layered materials, by various means, for applications in a wide array of technological and nano-technological fields (e.g. Coleman et al., 2011). The present study was undertaken to attempt to elucidate the mechanism of exfoliation of 'Vermiculite', which probably can be considered as the very first layered material to be exploited for this property. Our approach has been to combine precise mineralogical and chemical characterisation of a range of specimens in relation to their capacity to be exfoliated by both thermal and chemical means.

\section{MATERIALS AND METHODS}

\section{Samples studied}

Six samples were studied, one of pure phlogopite mica as a control and five composed mainly of 
vermiculites and hydrobiotites in varying amounts. Two samples labelled MK-1 and KL-2 were sampled in Tanzania at the Mikese area in Morogoro region and Kalalani area in Tanga region, respectively. A further sample of the classic Palabora vermiculite (PB) from Phalaborwa, South Africa, was supplied by Palabora Europe Ltd. Three additional samples were taken from The James Hutton Institute mineral collection; Ver-2 a specimen of 'Poole' vermiculite, believed to be from the Enoree district in S. Carolina, Ver-18 a sample from Glen Urquhart, Invernesshire, Scotland, and Phl-3, a large hand specimen of phlogopite originally obtained from R.F.D. Parkinson and Co. and used as the control true mica specimen.

\section{Mineralogical analysis}

All samples were initially crushed in a coffee grinder for a few minutes only to avoid structural degradation and sieved to obtain particle size fractions of 1-2 mm. For XRD analysis, $3 \mathrm{~g}$ of the sieved samples were mixed with water at a ratio of 4:1 (water: solid) and micronized by grinding in a McCrone mill for $12 \mathrm{~min}$, with the exception of the phlogopite sample Phl-3 which was notably more resistant to particle size reduction and was therefore milled for $24 \mathrm{~min}$. The resulting slurries were spray-dried directly from the mill at $130^{\circ} \mathrm{C}$ to obtain random powder specimens (Hillier, 1999). Identification of the mineral phases in the samples was carried out after recording the XRD patterns of the random powders using $\mathrm{Co}-K \alpha$ radiation selected by a diffracted beam graphite monochromator on a Siemens D5000 $\theta / \theta$ diffractometer. The scanning was carried out over a range of $2-75^{\circ}$ on the $2 \theta$ scale with $0.02^{\circ}$ steps and counting for 2 s/step. Quantitative analyses of random powder XRD patterns were carried out by a full pattern fitting method as described in Omotoso et al. (2006). Purified reference specimens were used as mineral standards. The objective of this analysis was to determine the proportion of individual minerals in the samples.

\section{Chemical analysis}

The chemical composition of the samples was determined by electron probe microanalysis (EPMA) using a Microscan MK7 equipped with an energy dispersive analyser (LINK Analytical
AN10/25S). The analysis was carried out using an accelerating voltage of $15 \mathrm{kV}$; probe current of $3.0 \mathrm{nA}$; take off angle of $75^{\circ} ; 30 \mu \mathrm{m}$ electron beam diameter; and counting time of 150 s. Standard minerals were used for calibration. Data were acquired and processed using the LINKS ZAF4/ FLS software at the University of Aberdeen, Department of Geology and Petroleum Geology.

Distribution of potassium in the samples (1-2 mm sized material) was studied using a scanning electron microscope (SEM) fitted with an X-ray energy dispersive system (EDS). The particles were mounted on glass slides and coated with a thin conducting layer of carbon to prevent the surface from charging (Hall \& Lloyd, 1981). The SEM instrument used was an ISI-ABT55 with EDS-LINK AN10/55S. The images were acquired with an ISS-I-SCAN 2000 Digital Image Acquisition System. The mapping was done with a $15 \mathrm{~ms}$ dwell time and a 512 pixel $\times 512$ pixel frame at the University of Aberdeen in the UK.

Additionally, selected samples were caesium $\left(\mathrm{Cs}^{+}\right)$exchanged by soaking overnight in solutions of 1 м CsCl (Hillier \& Clayton, 1992) followed by thorough rinsing in deionised water and the subsequent particle distribution of $\mathrm{Cs}^{+}$mapped by techniques similar to those employed for potassium mapping.

\section{Thermal exfoliation procedure}

The extent of exfoliation was measured as the coefficient of expansion (K) defined by Couderc \& Douillet (1973) as the ratio of bulk densities measured prior to and post flash-heating. Each sample was measured in triplicate using the precisely sized 1-2 $\mathrm{mm}$ materials separated by sieving. No attempt was made to remove impurities but XRD analysis (see below) showed that all samples contained phyllosilicate contents of greater than $92 \%$ by weight. For each sample precisely $2 \mathrm{~g}$ was weighed on an electronic balance. Sample volume was determined by tipping the loose fragments into a $5 \mathrm{ml}$ measuring cylinder, lifting $2 \mathrm{~cm}$ above the table and dropping gently 10 times to obtain a homogenous packing of the loose particles in the cylinder. Thereafter, separate specimens were flash-heated in a muffle furnace at 400 and at $900^{\circ} \mathrm{C}$ for three minutes. One minute was set for the temperature to equilibrate and two minutes as the holding time. The weight of the samples and their volumes were again determined 
immediately after heating. Heating at $400^{\circ} \mathrm{C}$ was aimed at assessing the effect of interlayer water loss only, compared to $900^{\circ} \mathrm{C}$ at which loss of both interlayer water and water derived from dehydroxylation of structural hydroxyl was expected. Additionally, ten large $\left(\sim 1 \mathrm{~cm}^{2}\right.$ sized $)$ flakes of sample KL-2 were also tested by flash-heating at $900^{\circ} \mathrm{C}$ under identical conditions to the $1-2 \mathrm{~mm}$ fraction samples.

\section{Chemical exfoliation procedure}

Following the results of thermal exfoliation tests, all original samples were also tested for their ability to be chemically exfoliated. This was conducted by immersion/contact of small aliquots of the 1-2 mm fractions consisting of several tens of particles with $30 \% \mathrm{H}_{2} \mathrm{O}_{2}$ overnight.

\section{RESULTS}

\section{Mineralogical composition}

The XRD patterns of the spray-dried random powders of the samples are presented in Fig. 1a and b, and quantitative analyses of the samples by the full pattern fitting method are given in Table 1. XRD results show that two of the samples (KL-2, Ver-18) are dominated by true vermiculite. Indeed, sample KL-2, shows no evidence of any other minerals. This sample appears to be $100 \%$ pure true vermiculite, with integral basal reflections based on a spacing of $\sim 14.4 \AA$ and additional non-basal peaks which conform precisely to the typical powder pattern of a trioctahedral vermiculite (Brindley \& Brown, 1984). Sample Ver-18 has an almost identical XRD pattern to that of KL-2, the only minor difference being the presence of some peaks which indicate that a minor amount of chlorite is also present in this sample. At low angles the chlorite basal peaks $(001,002)$ are coincident with basal peaks from the vermiculite but greater resolution occurs at higher angles (Fig. 1a). The control phlogopite also shown in Fig. 1a is confirmed as pure phlogopite mica with no evidence of any vermiculite either as a discrete phase or as an interstratification. Figure $1 \mathrm{~b}$ shows XRD patterns of the three samples PB, MK1 and Ver-2. Two of these samples, Ver-2 and MK-1 contain substantial true vermiculite, but both samples also contain substantial hydrobiotite (Table 1). The presence of hydrobiotite is indicated most obviously by strong but broad peaks at around 12 and $24 \AA$. The largest spacing peak is sometimes referred to as a superlattice peak since it arises from an ordered interstratification of $10 \AA$ (mica) and $14 \AA$ (vermiculite) layers. The term hydrobiotite has been precisely defined (Brindley et al., 1983) but we use it here in its most general sense to describe mica/vermiculite mixed-layer minerals, with sub-equal proportions of layer types, although it is likely that the specimens we have examined would conform to the strict definition. The similar name hydrophlogopite, although widely used by analogy, is discredited as a mineral name. Hydrobiotite is the dominant phase in sample PB accounting for about $95 \%$ of the sample, only a trace of true vermiculite being present in this sample. Both sample PB and Ver-2 also contain minor amounts of discrete phlogopite (Table 1). The presence of accessory minerals in vermiculites and hydrobiotites is common (Frank \& Edmond, 2001; Hindman, 2006) and other phases identified by XRD in the various samples include minor to trace amounts of quartz, amphibole and talc.

TABLE 1. Quantitative mineralogical composition of the six samples $(<2->1 \mathrm{~mm}$ sized) by full pattern fitting. Analytical uncertainties at 95\% confidence are given following the method described in Hillier (2003).

\begin{tabular}{lrrrrrrr}
\hline & Vermiculite & Hydrobiotite & Phlogopite & Chlorite & Talc & Quartz & Amphibole \\
\hline KL2 & $100.0 \pm 5.0$ & & & & & & \\
VER-18 & $92.0 \pm 4.9$ & & & $7.4 \pm 2.0$ & & $0.6 \pm 0.8$ & \\
VER-2 & $46.7 \pm 3.8$ & $34.6 \pm 3.5$ & $12.1 \pm 2.4$ & $0.5 \pm 0.8$ & $2.1 \pm 1.3$ & $2.1 \pm 1.3$ & $1.9 \pm 1.3$ \\
MK1 & $25.6 \pm 3.1$ & $62.1 \pm 4.2$ & & & & $5.1 \pm 1.8$ & $7.2 \pm 2.0$ \\
PB & & $94.6 \pm 4.9$ & $5.1 \pm 1.8$ & & & $0.3 \pm 0.7$ & \\
PHL-3 & & & $98.5 \pm 5.0$ & & & & \\
& & & & & & \\
\hline
\end{tabular}



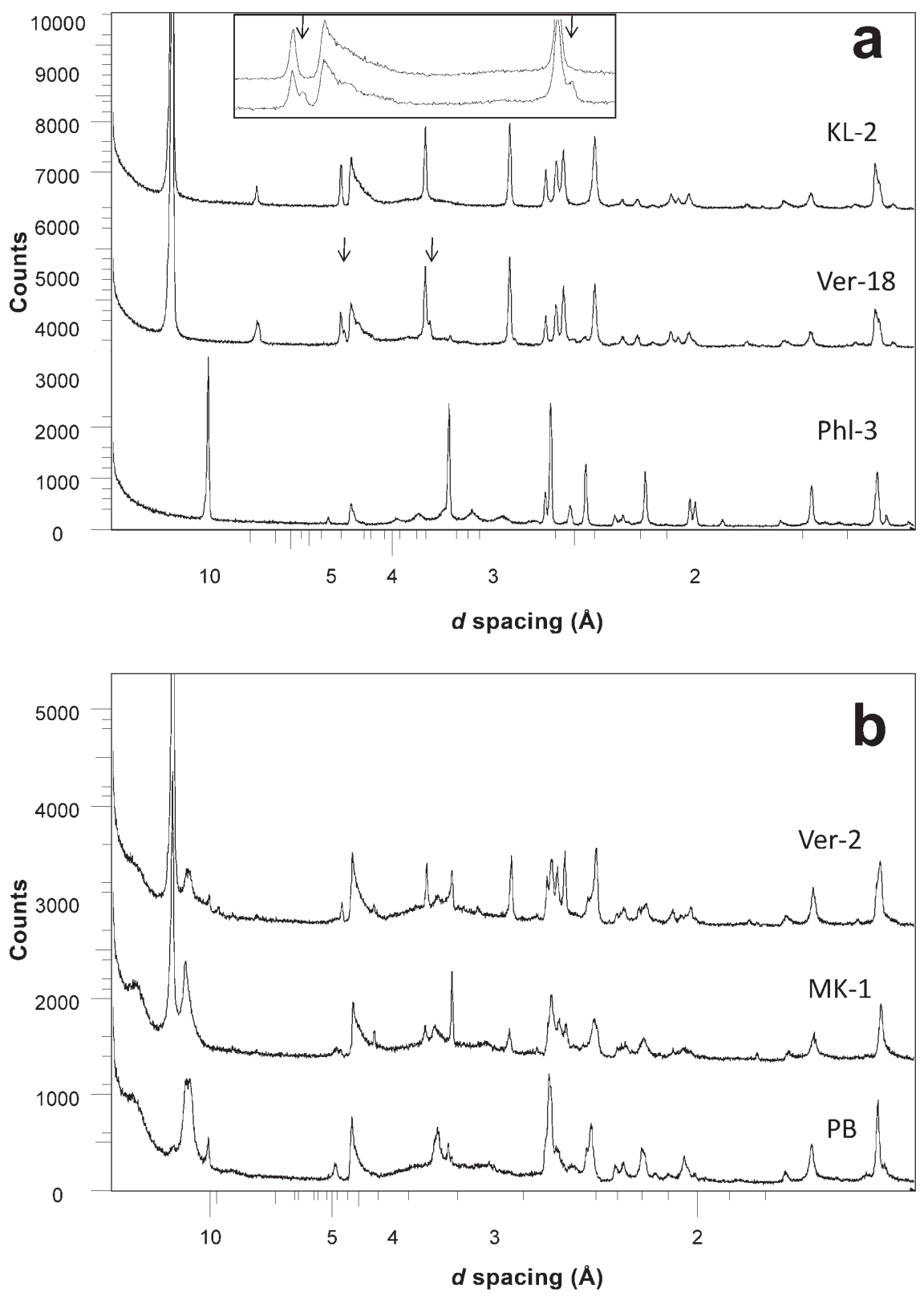

FIG. 1. (a) Random powder XRD patterns of samples KL-2 (pure vermiculite), Ver-18 (vermiculite, minor chlorite), and Phl-3 (pure phlogopite). Arrows show positions of chlorite 003 and 004 peaks in Ver-18, and insert expands this region for comparison of Ver-18 to KL-2. (b) Random powder XRD patterns of samples Ver-2 (vermiculite, hydrobiotite, phlogopite), MK-1 (vermiculite, hydrobiotite) and PB (hydrobiotite, phlogopite). Quantitative mineralogical compositions are given in Table 1.

\section{Chemical composition}

Spot EMPA analyses of particles from the different samples are given in Table 2. Based on the measured potassium contents most of the analyses can be classified into one of three discrete categories namely vermiculite $\left(<<1 \% \mathrm{~K}_{2} \mathrm{O}\right)$, phlo- 
gopite $\left(\approx 10 \% \mathrm{~K}_{2} \mathrm{O}\right)$, or hydrobiotite $\left(\approx 5 \% \mathrm{~K}_{2} \mathrm{O}\right)$. Some analyses with intermediate compositions were recorded, but they appear less common than discrete compositions. This classification is included in Table 2, using the abbreviations $\mathrm{V}, \mathrm{P}$, $\mathrm{HB}$ and mixtures thereof. For samples KL-2 and Ver-18, all analyses gave compositions that appear to be consistent with pure true vermiculite; no other compositions were recorded from these two samples. Sample Ver-2, also produced a set of analyses that was consistent with a pure vermiculite, and are in fact of rather similar composition to the vermiculite analyses recorded from KL-2 and Ver-18, but in addition the Ver-2 sample showed a complete range of compositions, with some analyses classified as hydrobiotite, others as probable mixtures of vermiculite and hydrobiotite (in the spot analysis volume) and one with a potassium content consistent with pure phlogopite. Similarly, sample MK-1 showed a range of different compositions but again polarized into groups that can be classified as either vermiculite or hydrobiotite compositions. Analyses of the PB sample from Palabora also appear to divide into two groups, one group of hydrobiotite type compositions and the other with potassium contents commensurate with pure phlogopite. Finally, as expected, the control mica Phl-3, showed analyses consistent only with that of a pure phlogopite. One further and very important point concerning the EPMA data, indeed one that determined our decision to map the particles for potassium distribution (see below), was that the variable compositions that were recorded for samples Ver-2, MK-1 and PB were not necessarily recorded from individual particles, but often from different spots on the same contiguous particle.

\section{Potassium distribution}

Mapping of potassium by SEM with EDS revealed that samples KL-2 and Ver-18 do not contain significant amounts of potassium (and see Table 2); consequently the micrographs of potassium distribution obtained were uniform and featureless. For particles from samples Ver-2 and MK-1, however, potassium mapping revealed a complex mosaic distribution of potassium across the particles (Fig. 2). The darkest areas of the micrographs correspond with the lowest potassium concentrations, and the brightest areas to the highest potassium concentrations. Thus, particles from
Ver-2 show a clearly defined patchwork of lowpotassium and high-potassium regions. For the most part the shapes of these different zones appear to be irregular and they are distributed quite evenly across the particles with sharp well defined boundaries between low- and high-potassium zones. In some instances there appear to be linear zones of low-potassium concentration connecting a network of patches of low-potassium distribution. In combination with the EMPA analyses of Ver-2 it is clear that the darkest patches are zones of vermiculite, the brighter patches are zones of hydrobiotite and the very brightest patches are zones of phlogopite. Particles from MK-1 show a similar distribution. Additionally, some particles are observed in both samples showing a more diffuse distribution and zoning of potassium, which may indicate less discrete zoning of the distribution of the different mineral phases throughout the volume of the particle, or perhaps zones that are deeper in the particle volume and/or tilted such that their boundaries have less obvious expression in the surface maps. Particles from the PB sample also show variation in the distribution of $\mathrm{K}^{+}$, but in these particles patches of very low potassium concentration are more or less absent and the zoning of potassium distribution appears somewhat more diffuse, but nonetheless still consistent with an irregular, patchy, distribution of hydrobiotite and phlogopite zones across many particles.

\section{Caesium distribution}

On the basis of the previous results, two samples were tested for their $\mathrm{Cs}^{+}$exchange properties, namely KL-2 and Ver-18, both being samples that XRD and EMPA analysis confirmed as essentially pure vermiculite. Several particles were exchanged with $\mathrm{Cs}^{+}$which was expected to completely replace the interlayer cations in these vermiculite particles so that the distribution of exchange sites could be mapped. Based on the EMPA results for these two samples the natural interlayer cations were expected to be dominated by exchangeable $\mathrm{Mg}^{2+}$, and fixed interlayer potassium was demonstrated as essentially absent (Table 2). This experiment is analogous to the mapping of potassium distribution in these samples but instead provides information on the distribution of cations in exchangeable interlayer sites rather than fixed potassium in interlayer sites. The distribution of $\mathrm{Cs}^{+}$found in sample KL-2 was uniform (Fig. 3), i.e. all interlayer sites were 
TABLE 2. Electron microprobe analyses from different samples and their classification. $\mathrm{V}=$ vermiculite, $\mathrm{HB}=$ hydrobiotite and $\mathrm{P}=$ phlogopite.

\begin{tabular}{|c|c|c|c|c|c|c|c|c|c|c|c|c|}
\hline Sample & $\mathrm{SiO}_{2}$ & $\mathrm{TiO}_{2}$ & $\mathrm{Al}_{2} \mathrm{O}_{3}$ & $\mathrm{Cr}_{2} \mathrm{O}_{3}$ & $\mathrm{Fe}_{2} \mathrm{O}_{3}$ & $\mathrm{MnO}$ & $\mathrm{MgO}$ & $\mathrm{CaO}$ & $\mathrm{Na}_{2} \mathrm{O}$ & $\mathrm{K}_{2} \mathrm{O}$ & Total & Mineral \\
\hline L-2 & 38.01 & 0.52 & 15.66 & 0.23 & 4.43 & 0.04 & 25.68 & 0.08 & 0.29 & 0.02 & 84.95 & $\mathrm{~V}$ \\
\hline KL-2 & 37.77 & 0.57 & 15.35 & 0.15 & 4.66 & 0.05 & 25.09 & 0.36 & 0.26 & 0.00 & 84.26 & V \\
\hline L-2 & 38.49 & 0.60 & 15.69 & 0.15 & 4.32 & 0.00 & 25.66 & 0.13 & 0.20 & 0.05 & 85.28 & V \\
\hline KL-2 & 39.13 & 0.59 & 15.87 & 0.20 & 4.53 & 0.07 & 26.55 & 0.07 & 0.20 & 0.00 & 87.21 & V \\
\hline KL-2 & 37.12 & 0.54 & 16.22 & 0.20 & 4.90 & 0.04 & 26.76 & 0.05 & 0.27 & 0.00 & 86.08 & V \\
\hline er-18 & 39.01 & 0.62 & 16.45 & 0.08 & 5.48 & 0.04 & 21.94 & 0.54 & 0.40 & 0.03 & 84.58 & V \\
\hline er-18 & 38.84 & 0.72 & 16.61 & 0.01 & 5.75 & 0.08 & 23.30 & 0.87 & 0. & & 40 & V \\
\hline Ver-18 & 34.36 & 0.61 & 18.79 & 0.20 & 5.77 & 0.09 & 26.57 & 0.30 & 0.30 & .23 & 87.21 & V \\
\hline Ver-18 & 41.94 & 0.56 & 15.95 & 0.12 & 5.46 & 0.06 & 22.97 & 0.00 & 0.39 & .03 & & V \\
\hline Ver-18 & 35.62 & 0.60 & 17.34 & 0.10 & 5.82 & 0.11 & 24.20 & 0.14 & 0.31 & .03 & 84.26 & V \\
\hline Ver-2 & 39.44 & 1.01 & 11.70 & $0.0 \mathrm{~S}$ & 5.00 & 0.00 & 25.79 & 0.17 & 0. & 07 & 83.47 & V \\
\hline Ver-2 & 41.16 & 0.57 & 12.11 & 0.04 & 4.50 & 0.01 & 27.86 & 0.08 & 0.3 & .11 & 86.77 & V \\
\hline Ver-2 & 41.44 & 0.54 & 11.59 & 0.00 & 4.56 & 0.05 & 27.13 & 0.06 & 0.2 & .14 & 85.73 & V \\
\hline Ver-2 & 40.97 & 1.45 & 12.24 & 0.42 & 7.91 & 0.06 & 22.15 & 0.11 & 0.17 & .33 & 85.80 & $\mathrm{~V}$ \\
\hline Ver-2 & 41.05 & 0.99 & 12.34 & 0.50 & 5.39 & 0.04 & 26.36 & 0.10 & 0.23 & 0.86 & 87.86 & V/HB \\
\hline er-2 & 41.02 & 1.68 & 12.02 & 0.43 & 8.43 & 0.08 & 22.13 & 0.10 & 0.32 & 1.80 & 88.00 & V/HB \\
\hline er-2 & 39.51 & 2.08 & 13.37 & 0 & 7. & 0. & 20.05 & 0.16 & 0. & 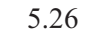 & & HB \\
\hline Ver-2 & 39.06 & 1.99 & 13.26 & 0.3 & 8.23 & 0.05 & 19.85 & 0.22 & 0 & 5 & 88.80 & HB \\
\hline Ver-2 & 39.49 & 2.21 & 13.5 & 0.07 & 10.96 & 0.16 & 18.23 & 0.07 & 0. & & 7 & HB \\
\hline Ver-2 & 39.13 & 2.30 & 13.39 & 0.00 & 12.19 & 0.04 & 17.34 & 0.00 & 0. & 6.8 & 91.44 & HB \\
\hline Ver-2 & 38.70 & 1.94 & 13.23 & 0.39 & 13.00 & 0.00 & 17.26 & 0.14 & 0.2 & 5 & 91.82 & $\mathrm{HB}$ \\
\hline Ver-2 & 40.86 & 2.31 & 12.69 & 0.17 & 9.67 & 0.07 & 20.27 & 0.02 & 0.28 & 9.10 & 95.42 & $\mathrm{P}$ \\
\hline MK-1 & 45.13 & 2.7 & 8 & 0 & 20. & 0 . & 2. & 2. & 0. & 0.16 & 8 & V \\
\hline $1 \mathrm{~K}-1$ & 40.86 & 1.00 & 14.75 & 0.0 & 16.8 & 0. & 2.02 & 1.51 & 0 . & 1 & 7 & V \\
\hline MK-1 & 39.30 & 0.87 & 16.43 & 0.1 & 16.8 & 0.3 & 7.72 & 1.32 & 0.1 & 3 & 83.35 & V \\
\hline MK-1 & 42.60 & 1.34 & 18.53 & 0.03 & 15.23 & 0.00 & 1.30 & 1.32 & 0.06 & 0.26 & 80.67 & V \\
\hline IK-1 & 40.97 & 0.91 & 11.12 & 0. & 24.57 & 0. & 3.28 & 1.80 & 0. & 0.3 & 41 & V \\
\hline MK-1 & 41.76 & 2.25 & 13.78 & 0.40 & 12.39 & 0.0 & 14.69 & 1.52 & 0. & 1.9 & 88.97 & V/HB \\
\hline MK-1 & 39.60 & 2.01 & 13.53 & 0.46 & 12.24 & 0.04 & 15.04 & 0.87 & 0.2 & 3.02 & 87.60 & V/HB \\
\hline MK-1 & 40.47 & 1.93 & 14.22 & 0.37 & 11.60 & 0.11 & 12.92 & 0.88 & 0.23 & 4.21 & 86.94 & HB \\
\hline MK-1 & 40.43 & 2.24 & 13.80 & 0.29 & 13.33 & 0.16 & 16.03 & 0.82 & 0.30 & 4.36 & 91.76 & HB \\
\hline MK-1 & 35.60 & 00 & 13. & 0 & 13.39 & 0. & 0 & 0. & 0. & 5.12 & 7 & HB \\
\hline MK-1 & 36.10 & 2.00 & 13.83 & 0.07 & 13.02 & 0.0 & 12.72 & 0.37 & 0. & 5.71 & 84.04 & HB \\
\hline MK-1 & 38.12 & 2.17 & 14.48 & $0.1^{1}$ & 13.9 & 0.0 & 12.28 & 0.56 & 0.2 & 5.96 & 87.97 & HB \\
\hline MK-1 & 37.63 & 2.33 & 14.41 & 0.13 & 14.28 & 0.19 & 12.46 & 0.55 & 0.33 & 6.08 & 88.37 & $\mathrm{HB}$ \\
\hline PB & 1 & & & & & & & & & & & HB \\
\hline PB & 42.47 & 1.06 & & & & & & 0.12 & & & & HB \\
\hline PB & 41.8 & 0.8 & 10. & & 6 & 0 & 2 & 0.05 & 0.1 & 6.05 & 1 & HB \\
\hline PB & 41.7 & 09 & 10.47 & 0.0 & 6.7 & $0 .($ & 25.63 & 0.04 & 0. & 6.07 & 92.06 & HB \\
\hline PB & 41.89 & 1.13 & 8.88 & 0.03 & 9.59 & 0.1 & 24.40 & 0.05 & 0.23 & 8.42 & 94.75 & $\mathrm{HB} / \mathrm{P}$ \\
\hline PB & 41.73 & 1.19 & 8.98 & 0.06 & 9.85 & 0.07 & 23.94 & 0.00 & 0.31 & 9.64 & 95.77 & $\mathrm{P}$ \\
\hline PB & & & & & 7.5 & & & 0.03 & 0 & & & $\mathrm{P}$ \\
\hline PB & 41.98 & 1.04 & 9.45 & 0.08 & 7.89 & 0.00 & 24.24 & 0.00 & 0.21 & 10.74 & 95.62 & $\mathrm{P}$ \\
\hline HL. & 4 & 0.9 & 1 & 0. & 3 & & 12 & 0. & 0. & 5 & 97 & $\mathrm{P}$ \\
\hline PHL-3 & 40.18 & 0.8 & 1 & 0. & 3 & & 8 & 0.16 & 3 & 28 & 94.02 & $\mathrm{P}$ \\
\hline PHL-3 & 40.42 & 1.0 & 13.46 & & 3.04 & $0 .($ & 24.69 & 0.02 & 0. & 10.12 & 93.32 & $\mathrm{P}$ \\
\hline HL-3 & 40.11 & 0.7 & & & 3.2 & & 24.87 & 0.04 & 0.5 & 10.08 & 93.17 & $\mathrm{P}$ \\
\hline PHL -3 & 40.6 & 10 & 14.14 & & 3.6 & & 24.5 & 0.00 & 0.71 & 10.21 & 94.92 & $\mathrm{P}$ \\
\hline PHL-3 & 39.63 & 0.92 & 13.89 & 0.00 & 3.52 & 0.08 & 24.39 & 0.19 & 0.42 & 10.26 & 93.30 & $\mathrm{P}$ \\
\hline PHL-3 & 40.83 & 1.0 & 13.7 & 0.0 & 2.90 & 0.0 & 24.93 & 0.06 & 0. & 10.11 & 94.04 & $\mathrm{P}$ \\
\hline PHL-3 & 40.10 & 1.09 & 13.97 & 0.00 & 3.14 & 0.04 & 24.60 & 0.00 & 0.43 & 10.00 & 93.37 & $\mathrm{P}$ \\
\hline
\end{tabular}



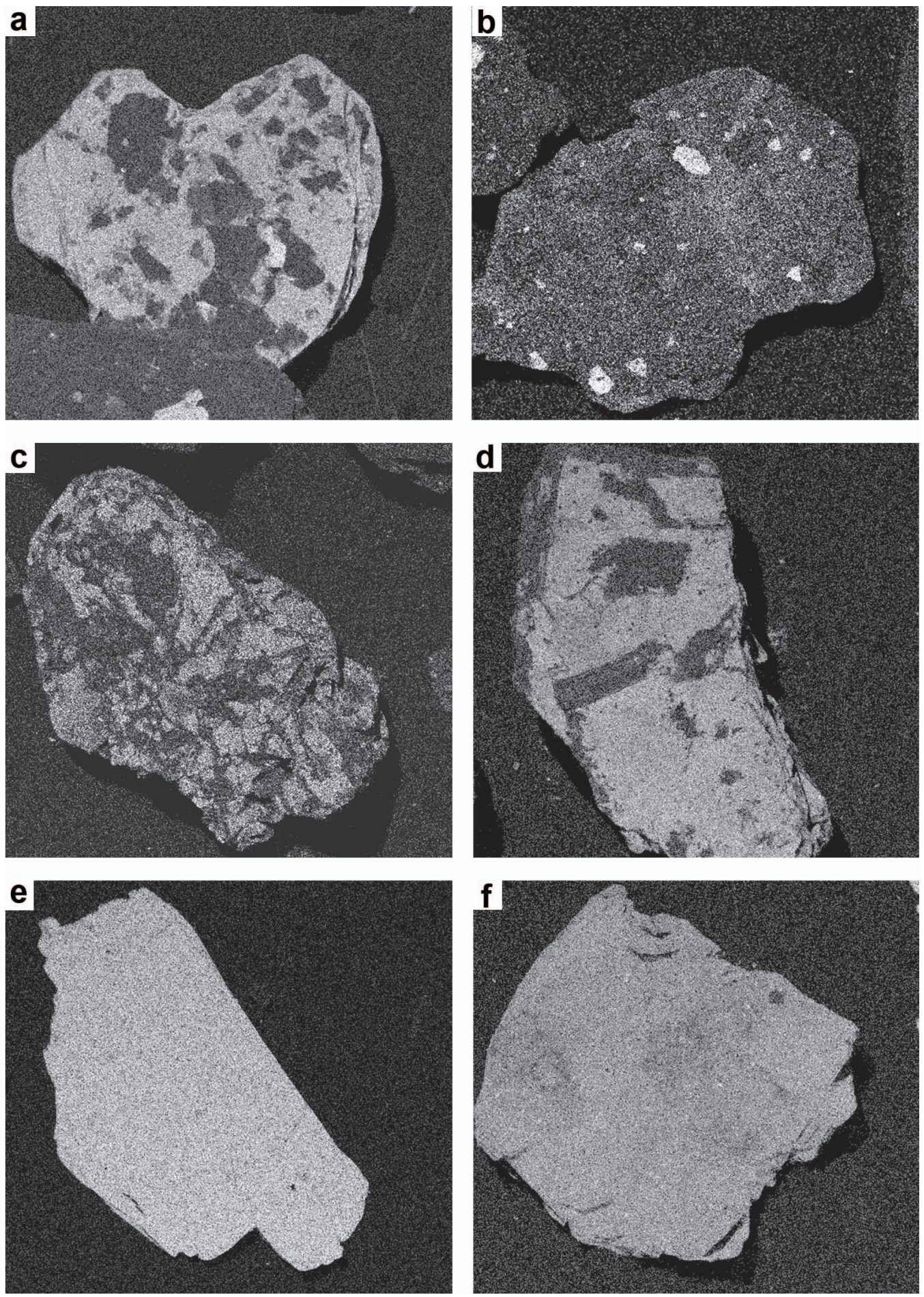

FIG. 2. Particles mapped for K distribution; bright areas indicate greater concentrations of K. (a) and (b) sample Ver-2, (c) and (d) sample MK-1, (e) and (f) sample PB. In all cases the field of view is $\sim 2 \mathrm{~mm}$. 

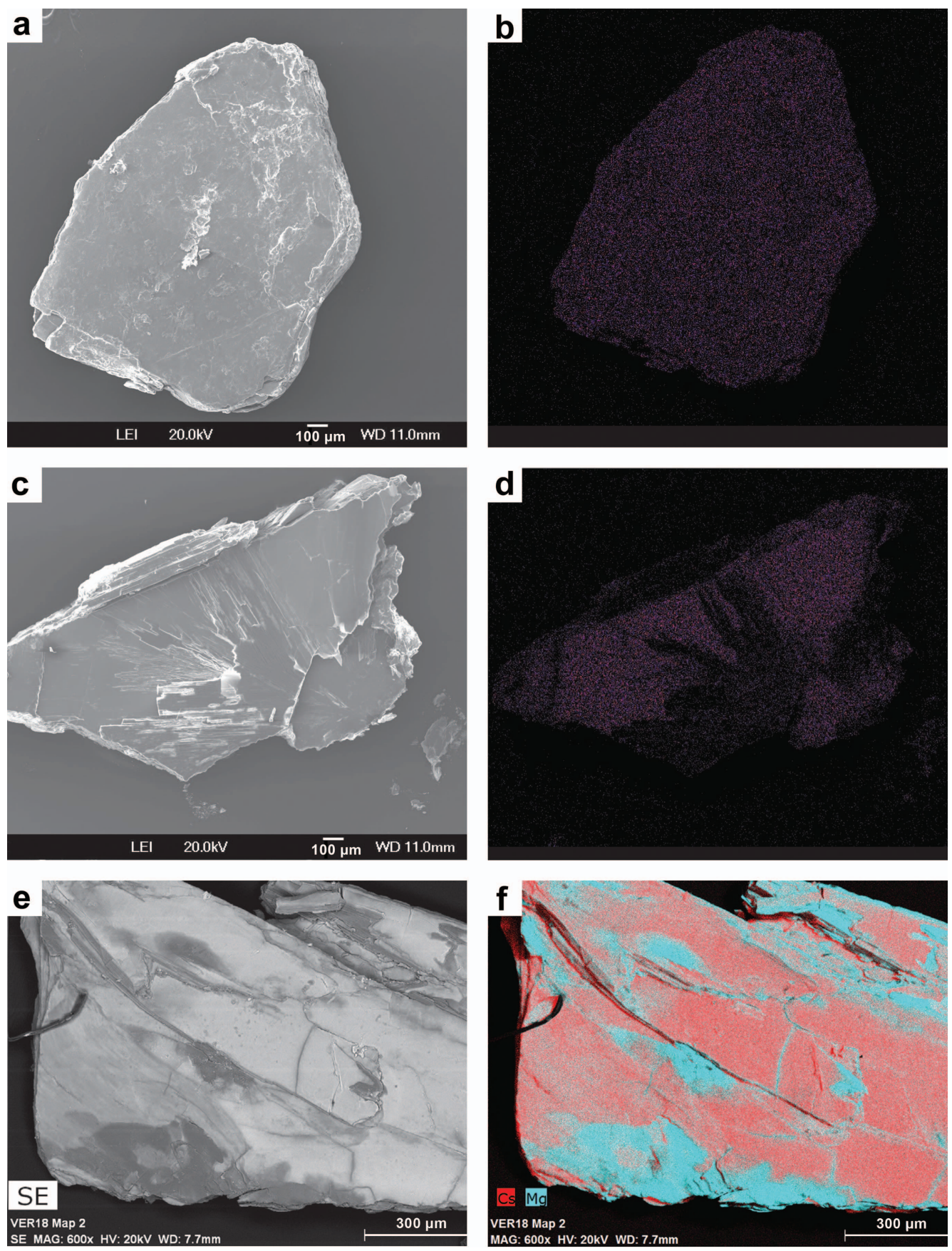

Fig. 3. Particles mapped for Cs (purple and magenta (b), (d), (f)) and $\mathrm{Mg}$ distribution (light blue (f)). (a) Secondary electron (SE) image of particle from sample KL-2, (b) Cs map of same particle showing uniform distribution of Cs throughout the particle volume, (c) SE image of particle from sample Ver-18, (d) Cs map of same particle showing patchy mosaic distribution of Cs indicating that some areas of this particle cannot exchange Cs. (e) SE image of particle from sample Ver-18, (f) same particle showing combined maps for Cs (magenta) and $\mathrm{Mg}$ (blue), areas which do not exchange Cs are correspondingly richer in $\mathrm{Mg}$. 
exchangeable so that $\mathrm{Cs}^{+}$was found evenly throughout the particles. In contrast, several of the particles tested for Ver-18, showed obvious regions where $\mathrm{Cs}^{+}$was unable to exchange. These regions appear as the darkest regions in the micrographs since they have low or no $\mathrm{Cs}^{+}$present, in contrast to other regions of the particles where $\mathrm{Cs}^{+}$exchange occurred readily. The presence of these regions in sample Ver-18 suggests that, although it has no obvious regions of fixed potassium, the interlayers of some regions are not occupied by exchangeable cations. In addition mapping for $\mathrm{Mg}$ after $\mathrm{Cs}^{+}$ exchange demonstrates that the regions void of $\mathrm{Cs}^{+}$ also have greater $\mathrm{Mg}$ contents than the regions where $\mathrm{Cs}^{+}$was able to exchange (Fig. 3). This pattern of distribution of $\mathrm{Cs}^{+}$absent zones across individual particles is reminiscent of the patch work or mosaic of potassium distribution noted in other samples, as well as being at a similar scale and it also reveals some similar thin linear features connecting the patches together.

\section{Thermal treatment}

Results of the flash-heating treatments to induce thermal exfoliation are summarized in Table 3 and photomicrographs of the specimens before and after heating to $900^{\circ} \mathrm{C}$ are shown in Fig. 4. The reference phlogopite mica Phl-3 had the lowest original bulk density (Table 3 ), probably due to the fact that the particles of this sample were notably thinner than other specimens (Fig. 4). Nonetheless, as expected, changes in bulk density were negligible for this specimen, and can be ascribed mainly to the small mass losses recorded, as a consequence of partial dehydroxylation. With a value of 1.1 (Table 3 ) the coefficient of expansion $(\mathrm{K})$ indicates that the phlogopite Phl-3 did not visibly exfoliate as can be confirmed from visual inspection (Fig. 4). The sample showing the largest $(\mathrm{K})$ value of 6.0 indicating that it was extensively exfoliated was MK-1. Mass loss for this sample at $900^{\circ} \mathrm{C}$ was $15.2 \%$ and implies a large contribution from interlayer water, although if measured simply in terms of a volume change (Table 3 ) by far the largest contribution to its decreased bulk density is the five-fold increase in volume due to exfoliation of the particles. Samples Ver-2, PB and Ver-18 also all showed significant exfoliation (Fig. 4), with (K) values of 5.0, 4.2 and 3.4, respectively, for heating at $900^{\circ} \mathrm{C}$ (Table 3). For all samples which exfoliated at $900^{\circ}$ some exfoliation was observed

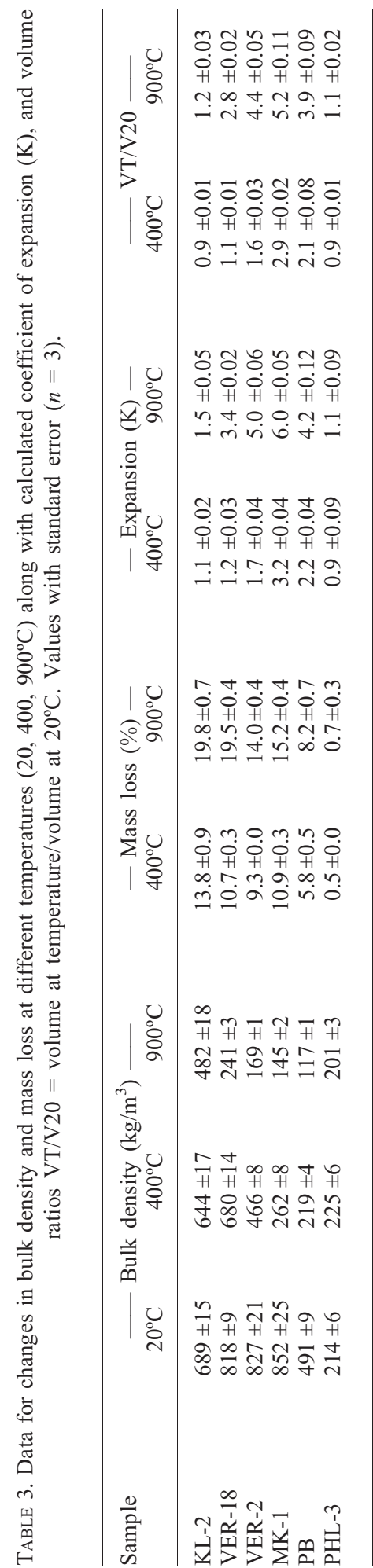



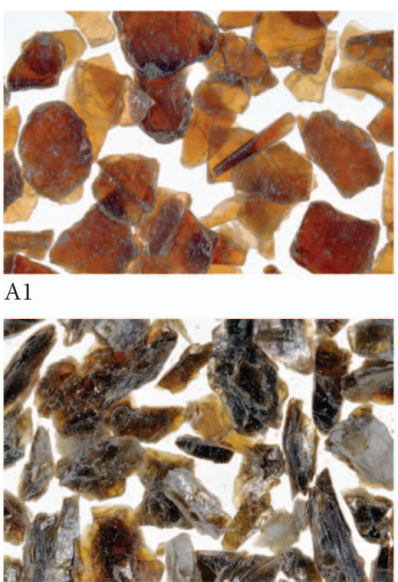

B1

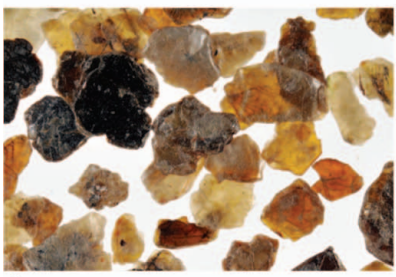

C1

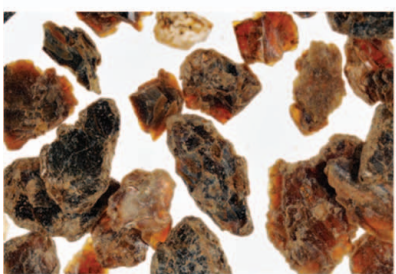

D1

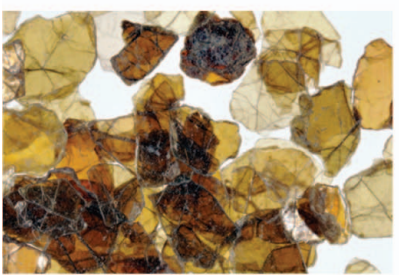

E1

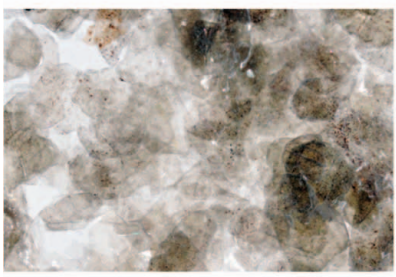

F1
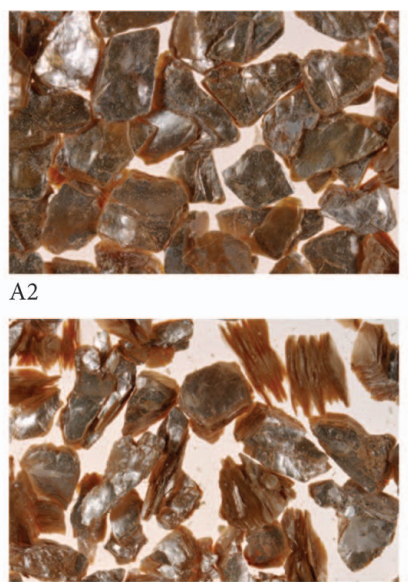

B2

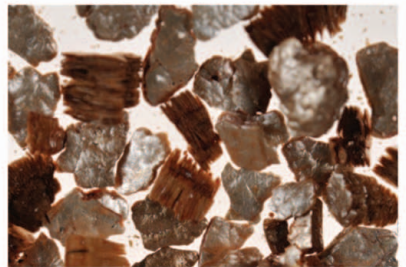

C2

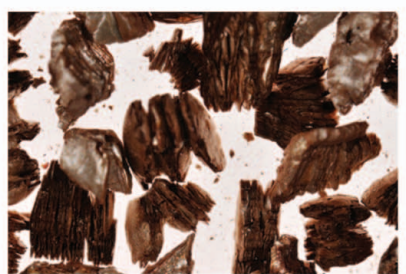

D2

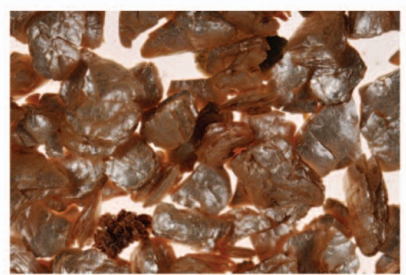

E2

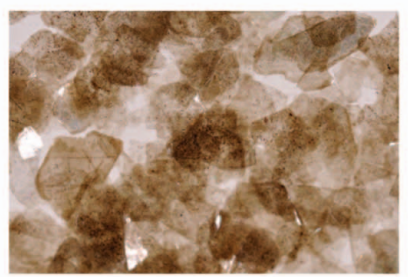

F2

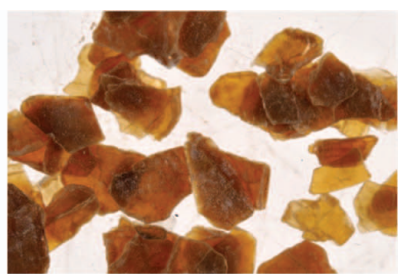

A3

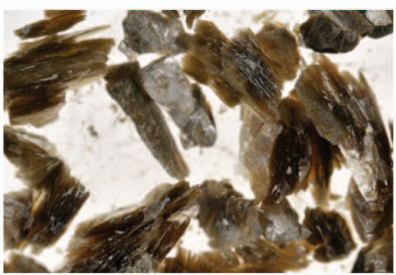

B3

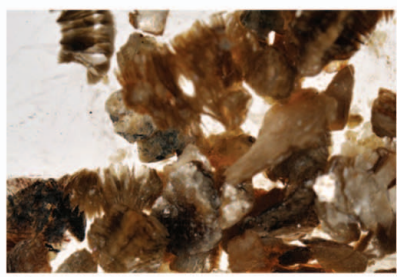

C3

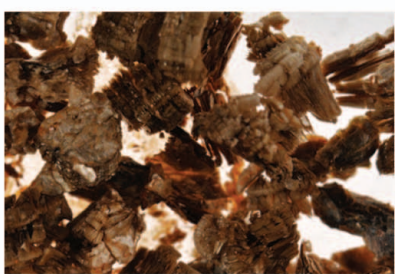

D3

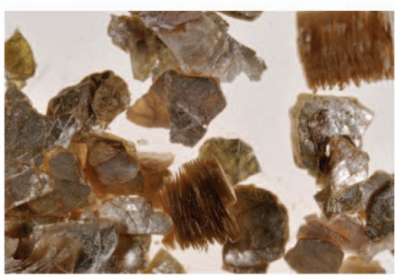

E3

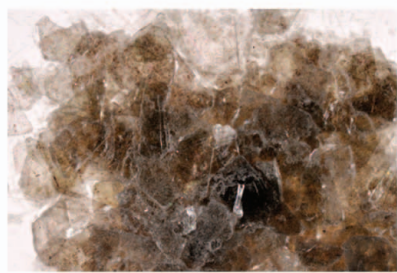

F3

FIG. 4. Photomicrographs of samples before exfoliation (column 1) and after thermal (column 2) and $\mathrm{H}_{2} \mathrm{O}_{2}$ (column 3) exfoliation. Row A: KL-2, row B: Ver-18, row C: Ver-2, row D: MK-1, row E: PB, row F: Phl-3. Samples KL-2 and Phl-3 show no visible exfoliation; all other samples show ready exfoliation with both thermal and $\mathrm{H}_{2} \mathrm{O}_{2}$ treatment. 
also at $400^{\circ} \mathrm{C}$, and generally speaking the extent of exfoliation observed at $400^{\circ} \mathrm{C}$ was approximately half of that observed at $900^{\circ} \mathrm{C}$. In contrast, sample KL-2 showed quite a different behaviour. Despite losing $19.8 \%$ mass when heated to $900^{\circ} \mathrm{C}$, a value that compares well with the theoretical weight loss expected from both complete dehydroxylation $(\approx 5 \%)$ and removal of the two layers of water associated with the interlayer cations $(\approx 15 \%)$ in a pure vermiculite, the measured coefficient of expansion was only 1.5 . Visually this sample showed no obvious signs of exfoliation (Fig. 4), although the colour changed to the typical golden one often observed for most specimens after heating, the particles appeared notably more brittle to the touch, and at high magnification the surface of the particles show numerous slightly raised blister-like areas. Thus, for sample KL-2 the deviation of the $(\mathrm{K})$ value from unity is ascribed mainly to the effect of the large weight loss on bulk density. Measured as a simple volume ratio (VT/V20 in Table 3) the deviation from unity is less than that measured as a bulk density ratio (1.2 compared to 1.5). This indicates that although exfoliation is not observed some minor volume expansion of the particles may have taken place, this behaviour being very similar to that of the pure phlogopite Phl-3. In summary, the sample KL-2, the purest vermiculite sample examined, does not visibly exfoliate in response to thermal shock. Because of this somewhat unexpected result, larger particles of approximately $1 \mathrm{~cm}^{2}$ area of sample KL-2 were also examined following heating to $900^{\circ} \mathrm{C}$. As with the smaller $1-2 \mathrm{~mm}$ particles, no visible signs of any exfoliation were observed for these larger particles of sample KL-2.

\section{Chemical exfoliation}

Each sample was also tested for its ability to exfoliate when treated with $\mathrm{H}_{2} \mathrm{O}_{2}$. These tests showed that after several hours of either immersion or simply wetting in $\mathrm{H}_{2} \mathrm{O}_{2}$, samples of $\mathrm{PB}, \mathrm{MK}-1$, Ver-2 and Ver-18 all exfoliated readily, whereas Phl-3 and KL-2 showed no reaction whatsoever (Fig. 4). Thus, the ability of any one sample to be exfoliated chemically mirrored the ability to be exfoliated by thermal shock. Although no attempt was made to quantify exfoliation by measuring the coefficient of expansion $(\mathrm{K})$ the impression gained was that many individual particles probably exfoliated to a greater degree in $\mathrm{H}_{2} \mathrm{O}_{2}$ than by thermal shock. A time lapse video (seven hours real time) of a single particle of the PB sample undergoing chemical exfoliation following wetting by $\mathrm{H}_{2} \mathrm{O}_{2}$ is deposited in the 'Images of Clay Archive' (http://www.minersoc.org/photo. php?id=149). Close inspection of the early stages of expansion when the particle was still wet with $\mathrm{H}_{2} \mathrm{O}_{2}$, clearly shows bubbles of gas escaping around the edges of the particle. In a separate experiment with approximately $10 \mathrm{~g}$ of sample $\mathrm{PB}$ the gas generated by treatment with $\mathrm{H}_{2} \mathrm{O}_{2}$ was confirmed as oxygen by its ability to re-ignite a glowing splint.

\section{DISCUSSION}

Both XRD and EMPA data from the six samples studied are internally consistent in their characteristics. Thus, the two samples KL-2 and Ver-18 have diffraction patterns consistent with pure true vermiculites. This is verified by their chemical compositions which, in so far as they show the essential absence of potassium, confirm the absence of mica in these specimens. In contrast, samples Ver-2, MK-1 and PB, were shown by XRD analysis to be multi-phase mixtures of vermiculite, hydrobiotite and phlogopite (Table 1). The multiphase composition was confirmed by the variability of the chemical analyses obtained by EMPA, and mapping for potassium demonstrated that the different phases are most commonly present as discrete zones within the same particle. The arrangement of these zones is often mosaic-like due to sharp intra-particle boundaries between zones or patches of one phase and zones or patches of another. In other words, although some particles are present as discrete physically separable phases, for the most part the different phases detected by XRD are present as multiphase particles.

In terms of their expansion characteristics, the three mixed phase samples, all with some proportion of hydrobiotite, also showed the greatest degree of exfoliation with $(\mathrm{K})$ values of between 4.2 and 6.0 for shock heating at $900^{\circ} \mathrm{C}$. In contrast the two single phase vermiculite samples Ver-18 and KL-2 showed the lowest $(\mathrm{K})$ values of 3.4 and 1.5 respectively for heating at $900^{\circ} \mathrm{C}$. These observations are completely in accord with those of other workers who have often demonstrated that samples that are poly-phase and/or rich in hydrobiotite exfoliate more readily compared to samples that are rich in true vermiculite (Midgley \& Midgley, 1960; Couderc \& Douillet, 1973; Justo et al., 1989). 
For example, four of the samples examined by Justo et al. (1989) were designated as true vermiculites and showed $(\mathrm{K})$ ratios ranging from 1.7 to 3.7, compared to values of 6.2 and 9.0 for two other mixed phase samples with components of vermiculite, mica/vermiculite and mica. Similarly, the data of Courdec \& Douillet (1973) indicate (K) values of 3.0 and 4.4 for two pure vermiculite samples and values often double these (average $=6.6$ ) for all other samples; all of which contained mixed-layer mica/vermiculite components, and all of which were poly-phase. In addition to characterising their samples by XRD both Justo et al. (1989) and Courdec \& Douillet (1973) provided chemical analyses of their samples demonstrating the essential absence of potassium in those samples designated as pure vermiculites. These pure vermiculite specimens are therefore comparable in their XRD and chemical data to Ver-18 and KL-2 of the present study. Thus, in summary there appear to be two broad categories in relation to mineralogical properties and their relationship to exfoliation behaviour; one category includes the polyphase specimens usually with a significant hydrobiotite component that tend to show the largest degree of exfoliation, whilst the other category includes the apparently pure vermiculites, which exfoliate far less and in some cases, such as KL-2 of the present study, essentially not at all. Figure 5 illustrates the distinction of these two groups very clearly in a plot of exfoliation measured as $(\mathrm{K})$ the coefficient of expansion (i.e. original bulk density/ exfoliated bulk density) vs. potassium content measured as $\mathrm{K}_{2} \mathrm{O}$.

Despite the long standing study of the exfoliation of vermiculite samples, as pointed out by HellerKallai (2006), no satisfactory explanation for this behaviour has yet been offered. Most authors agree without question that thermal shock exfoliation is related to the escape of the steam that is produced by the sudden heating of interlayer water molecules. Given the high temperatures involved, an additional complimentary contribution from water (steam) formed during dehydroxylation of the hydroxide molecules of the octahedral sheets is also possible. However, several authors have shown that exfoliation may begin at temperatures at low as $200^{\circ} \mathrm{C}$, and our experiments conducted at $400^{\circ} \mathrm{C}$ are below the dehyroxylation temperature of all 2:1 clay minerals (Mackenzie, 1957; Paterson \& Swaffield, 1987), confirming that dehydroxylation is not a prerequisite for exfoliation to occur. Nevertheless, although an instantaneous conversion of water to steam provides a logical and attractive explanation for a driving force for thermal exfoliation it falls short of providing a complete explanation because despite having the largest interlayer water contents, the most vermiculitic samples invariably show the lowest degree of expansion (Fig. 5). Indeed, one of the samples examined in the present study, sample KL-2, essentially failed to exfoliate at all. With a (K) value of just 1.5 for the $1-2 \mathrm{~mm}$ particles flash-heated to $900^{\circ} \mathrm{C}$ for 3 minutes, the sample KL-2 is very similar to the RJ-2 sample described by Justo et al. (1989), from Santa Olalla, which for particles sized to around $5 \mathrm{~mm}$ maximum diameter gave a $(\mathrm{K})$ value of 1.7 when heated at $900^{\circ} \mathrm{C}$ for $15 \mathrm{~min}$. Thus, in summary the true vermiculite group shows less, little or no exfoliation compared to the hydrobiotite group. Clearly any mechanistic understanding of thermal exfoliation has to be able to explain the behaviour of both of these mineralogical groups.

Walker (1961) indicated that exfoliation is related to particle size, and it seems well established in industry that the bulk density of exfoliated products is inversely related to the particle size of the feed (Suvorov \& Skurikhin, 2003), reflecting less exfoliation by finer particle sizes compared to larger ones. Interestingly, Marcos \& Rodríguez (2011), working on microwave exfoliation of vermiculite from Santa Olalla, noted that particles of $<3 \mathrm{~mm}$ diameter did not exfoliate at all, whereas larger particles did. Vermiculites from Santa Olalla have been studied quite extensively (de la Calle et al., 1988; Justo et al., 1989), and in terms of the two groups identified on Fig. 5 it appears that specimens for which published XRD and chemical data are available have characteristics that would place them into the true vermiculite dominated category rather than the $\mathrm{mica} /$ vermiculite dominant category. In order to check for the possible influence of particle size on the exfoliation of pure vermiculite sample KL-2, which failed to exfoliate for a particle size of $1-2 \mathrm{~mm}$, we also tested particles $\sim 1 \mathrm{~cm}^{2}$ flashheated at $900^{\circ} \mathrm{C}$, but even for this much larger particle size this sample failed to exfoliate.

In addition to testing thermal exfoliation, we also tested all samples for their ability to be chemically exfoliated. We did not measure the extent of exfoliation but simply observed if exfoliation occurred or not. For $\mathrm{H}_{2} \mathrm{O}_{2}$ the results showed that all samples exfoliated following contact with $\mathrm{H}_{2} \mathrm{O}_{2}$ 
when left overnight, except for two samples KL-2 and Phl-3. As observed previously by Üçgül \& Girgin (2002) exfoliation occurred simply with contact and wetting of the specimens by $\mathrm{H}_{2} \mathrm{O}_{2}$. $\mathrm{KL}-2$ is a pure vermiculite sample whilst Phl-3 is the reference control pure phlogopite. Therefore, these tests show that the behaviour of all six samples in terms of their ability to be chemically exfoliated by $\mathrm{H}_{2} \mathrm{O}_{2}$ mirrors their behaviour for thermal treatment (Fig. 4). The conclusion that can be drawn from these chemical tests is that whatever properties of the particles promote thermal exfoliation they are relevant also for exfoliation by $\mathrm{H}_{2} \mathrm{O}_{2}$. This suggests that the mechanisms of both thermal and $\mathrm{H}_{2} \mathrm{O}_{2}$ chemical exfoliation share one or more common factors.

To return to the specific mechanism of thermal exfoliation, the discovery that the poly-phase character of the hydrobiotite dominant group of samples is a feature that is expressed in individual particles suggests that this mosaic-like structure with its division into discrete well defined domains of more or less vermiculitic character is a key feature of the propensity of this group to exfoliate. Although we have only mapped this mineralogical mosaic structure based on the distribution of potassium, as determined from a probe of the particle surface, because the mosaic involves sharp transitions from one phase to another it must presumably have a structure that involves sharp well defined transitions along the plane of the layers, i.e. from layers which are vermiculite to layers which are mica. Such transitions would be expected within the volume of the particle in a manner determined by the extension of the mosaic structure throughout the particle. The essential difference between such layers is that vermiculite contains exchangeable hydrated cations, e.g. $\mathrm{Mg}^{2+}$, whereas layers of mica have fixed un-hydrated ions of potassium keyed into the ditrigonal cavities of adjacent 2:1 layers. With such transitions occurring throughout and within the volume of most particles one can envisage that the escape of steam produced from the interlayer water of vermiculite layers during thermal shock may be inhibited or impeded where vermiculite layers are laterally transitional to mica layers. Presumably, this inhibition may result in a build-up of pressure only relieved by forcing the layers apart to allow the steam to escape, i.e. exfoliation is the result. In terms of the poly-phase

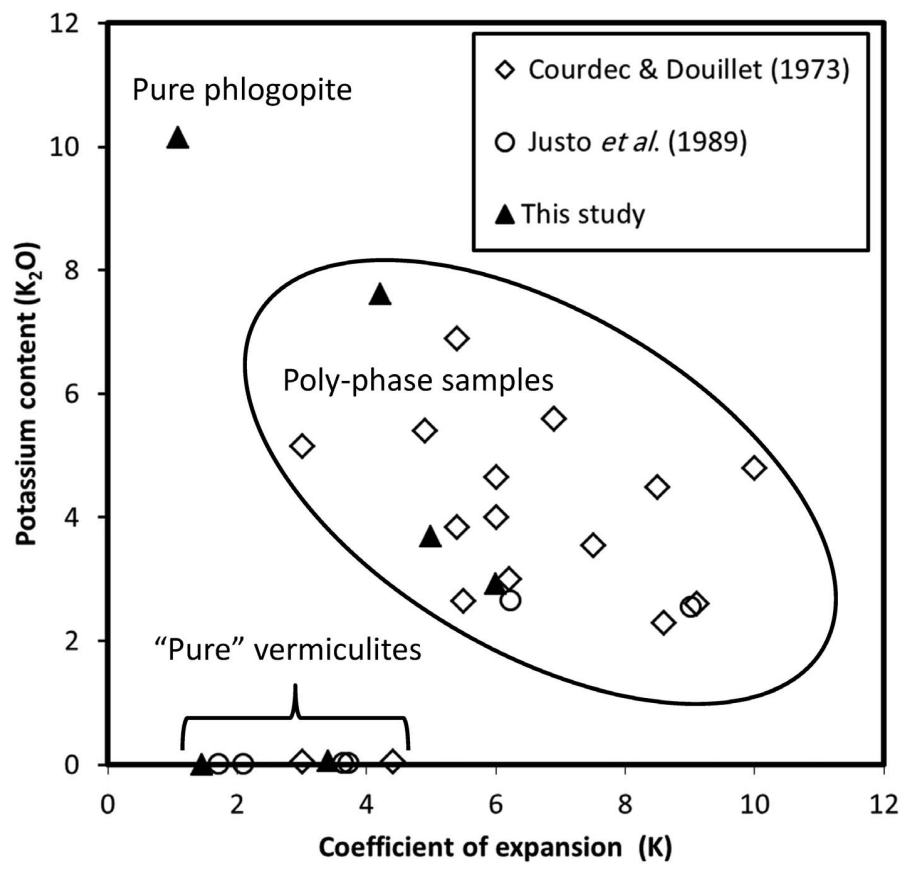

FIG. 5. Exfoliation measured as coefficient of expansion (K), i.e. original bulk density/exfoliated bulk density, vs. potassium content $\left(\mathrm{K}_{2} \mathrm{O}\right)$. 
nature of individual particles, lateral transitions of vermiculite to mica layers could occur with any combination of vermiculite, hydrobiotite or mica phase domains depending on the specific details of the mosaic arrangement. As such, particles consisting of vermiculite and hydrobiotite, or vermiculite and mica, or hydrobiotite and mica or even hydrobiotite alone, provided there were lateral transitions of vermiculite to mica layers, would all have capacity to impede the escape of steam under thermal shock. An additional attraction of this mosaic structure explanation for the mechanism of thermal exfoliation is that it can explain the particle size dependence of this phenomenon. Hence, for any given average size of the phase domains in the mosaic structure, once the particle size begins to approach or becomes smaller than this domain size, exfoliation would no longer occur because the escape of steam would no longer be impeded at intra-particle phase boundaries.

Although this explanation for exfoliation can be applied to the obviously poly-phase samples that constitute the hydrobiotite group of Fig. 5, at first sight it does not appear to provide an applicable explanation for the exfoliation behaviour of the true vermiculite group. For example, in the present study the XRD patterns and potassium contents of samples KL-2 and Ver-18 are essentially identical, yet sample KL-2 does not exfoliate whereas in obvious contrast Ver-18 exfoliates quite readily (Fig. 4). However, exchanging the interlayer cations of these samples with $\mathrm{Cs}^{+}$and then mapping the distribution of $\mathrm{Cs}^{+}$revealed that there are in fact differences in particle structure between these two samples. Thus KL-2 showed a uniform distribution of $\mathrm{Cs}^{+}$indicating that the cations in the interlayer region of KL-2 are uniformly and completely exchangeable. Ver-18, however, shows obvious regions where $\mathrm{Cs}^{+}$failed to exchange, which like the hydrobiotite group of samples seem to form intra-particle domains. A likely explanation for the inability of $\mathrm{Cs}^{+}$to exchange into these regions is that they do not contain exchangeable cations, but are instead local domains of brucite-like interlayer hydroxide. In other words, they are local zones of chlorite, present within the vermiculite particles. Chlorite was in fact observed by XRD in sample Ver-18 and although it was initially assumed that it was present as a discrete particulate phase, the $\mathrm{Cs}^{+}$ mapping indicates that chlorite is, at least in part, intergrown with the dominant vermiculite. Further support for this interpretation is provided by the fact that the $\mathrm{Mg}^{2+}$ concentration is clearly elevated in these zones post $\mathrm{Cs}^{+}$exchange (Fig. 3), precisely the chemical signature that would be expected from a fixed interlayer brucite sheet compared to exchangeable interlayer sites.

In the same way that intergrown domains of vermiculite, hydrobiotite and mica present a particle structure with the potential to impede the release of steam during thermal exfoliation, so too would a mosaic structure composed of intergrown vermiculite and chlorite. In essence the presence of chlorite in vermiculite can be envisaged as little more than a change from exchangeable interlayer $\mathrm{Mg}^{2+}$ to a fixed magnesium hydroxide interlayer. In an intergrown structure the transition from hydrated cation to fixed hydroxide may occur laterally along a contiguous interlayer space such that brucite interlayers could act in an analogous way to potassium in mica layers by physically blocking the escape of steam during flashheating. Once again pressure release would then only be achieved by exfoliation of the layers. In support of this mechanism it is pertinent to note that all of the 'pure' vermiculites examined by Justo et al. (1989) show evidence of dehydroxylation endotherms between 500 and $600^{\circ} \mathrm{C}$ in their DTA traces. Although Justo et al. (1989) preferred to interpret these features as evidence of mica layers in the vermiculite, this interpretation is inconsistent with the essential absence of potassium as shown by their own chemical analyses. We suggest that the endotherms are more likely evidence of dehydroxylation of brucite interlayers, the presence of which suggests the potential for a mosaic structure in these vermiculite samples with its capacity to impede the escape of steam during thermal shock resulting in particle exfoliation. Although the presence of domains of chlorite layers in vermiculite can often be detected by XRD, it is well established that DTA is potentially a more sensitive technique for their detection (Paterson \& Swaffield, 1987). As mentioned above, we did in fact identify a minor amount of chlorite in sample Ver-18 by XRD and although the tacit assumption usually made is that the chlorite identified by XRD is present as discrete particles, the evidence from $\mathrm{Cs}^{+}$saturation indicates that at least some chlorite is also present in intimate intra-particle intergrowth or interstratification with the dominant true vermiculite phase.

A cartoon of the mosaic structure and how it explains the phenomenon of exfoliation is shown in Fig. 6. In essence the mosaic structure is envisaged to act as a maze to escaping gases, with some dead 


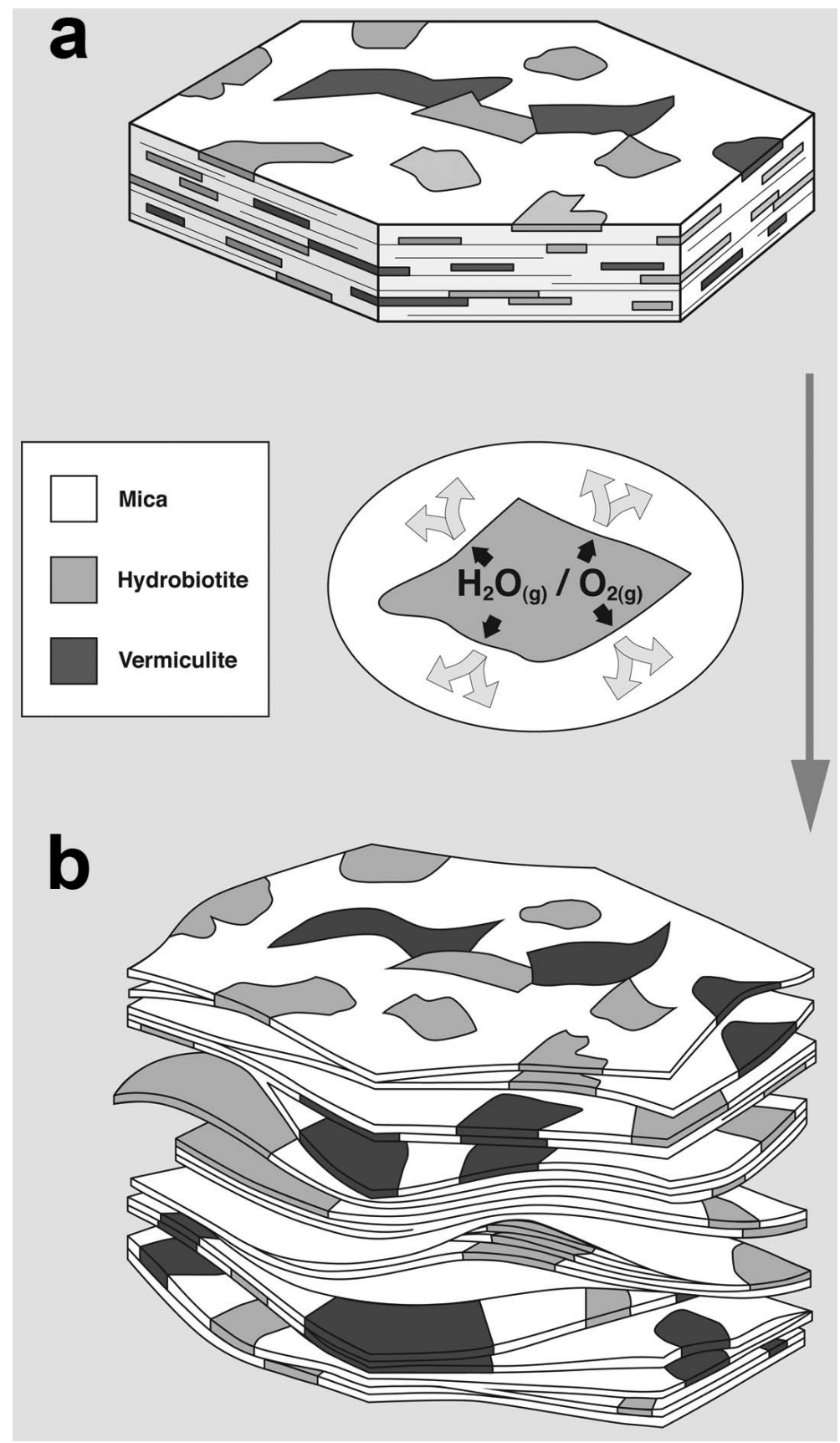

FIG. 6. Mechanism of exfoliation: (a) particle variously consisting of intergrown mosaic of vermiculite, hydrobiotite and mica domains (or vermiculite and chlorite domains). Gas phases produced by shock thermal treatment, or breakdown of hydrogen peroxide are trapped in dead ends at phase boundaries causing pressure build up. The result (b) is exfoliation of the layers. 
ends becoming pressure points and subsequently acting as nuclei for the initiation of the exfoliation process. Thus exfoliation is necessary to relieve the pressure build up, and is triggered at dead-end pressure points when the force applied by the gas pressure exceeds the forces bonding the phyllosilicate layers together (Giese, 1978). Presumably the requirement for the force due to pressure buildup to exceed the forces bonding the layers together may also explain the temperature dependence of thermal exfoliation. In terms of the relationship between thermal and chemical exfoliation the mosaic structure can also be envisaged as the common factor that underlies the capacity of any sample to exfoliate or not, whether by thermal or $\mathrm{H}_{2} \mathrm{O}_{2}$ chemical means. Thus, exfoliation with $\mathrm{H}_{2} \mathrm{O}_{2}$ has long been suggested to be due to the decomposition of $\mathrm{H}_{2} \mathrm{O}_{2}$ and the evolution of molecular oxygen as a gas phase (Groves, 1939), probably catalysed by elements such as $\mathrm{Fe}$ or Mn (Drosdorff \& Miles 1938) in a Fenton-like reaction. Since the overall decomposition of the $\mathrm{H}_{2} \mathrm{O}_{2}$ produces a gas phase, i.e. $\mathrm{O}_{2}$, the impedance of the escape of the evolved $\mathrm{O}_{2}$ by the mosaic structure can be offered as the common denominator in the explanation for exfoliation by this chemical means. Presumably the liquid $\mathrm{H}_{2} \mathrm{O}_{2}$ initially exchanges readily into the vermiculite layers within a particle, facilitated by the linear features that seem to network vermiculite patches together. When $\mathrm{H}_{2} \mathrm{O}_{2}$ decomposition begins it must quickly reach a rate that exceeds the ability of $\mathrm{O}_{2}$ to diffuse back out of the mosaic structure and, in an analogous fashion to flash heating, the gas pressure that results is sufficient to exfoliate the layers. Interestingly, as well as demonstrating the escape of $\mathrm{O}_{2}$ gas from the edges of the particles, the video recording of the $\mathrm{H}_{2} \mathrm{O}_{2}$ exfoliation of the particle of the PB sample (http://www.minersoc.org/photo. php?id=149) shows that there is an elastic-like partial contraction of the volume of the particle as the process comes to completion. It is almost as if the particle is overinflated by the process of the escaping gas and there is a relaxation once the gas has all finally escaped from the particle. Overall, a particle of around 0.1 $\mathrm{mm}$ thickness will consist of some 70 to 100 thousand individual 2:1 vermiculite or mica layers. The accordion-like vermiform particles that form on exfoliation usually show cleavage, opening and obvious separation of only some tens to several tens of layers per particle, so presumably only a relatively small number of layers per particle are exfoliated as a result of pressure build up at dead ends. In summary, both the processes of thermal and $\mathrm{H}_{2} \mathrm{O}_{2}$ exfoliation can be understood in terms of how the structure and arrangement of different phases throughout the volume of a particle impede the escape of gas resulting in a build-up of pressure that is eventually released by exfoliation of the layers. A similar explanation for the thermal exfoliation of silicon wafers by hydrogen gas was offered by Weldon et al. (1997). The mosaic structure and the intra particle phase transitions found in vermiculite samples can be considered as analogous in function to the defects in silicon. Indeed, the role that defect structure may play in the exfoliation behaviour of other layered materials may warrant further investigation.

Our model can also offer a possible explanation for the unexplained observations that the onset temperature of thermal exfoliation can be lowered by exchange with cations such as $\mathrm{Na}^{+}, \mathrm{K}^{+}$or $\mathrm{NH}^{+}$ (e.g. Muiambo et al., 2010; Huo et al., 2012). Potentially, all of these cations can be fixed in interlayer positions, especially at points of high layer charge. Such a process has the potential to increase the tortuosity of gas escape from the particles and consequently the probability of deadend pressure points, which are required in our model to act as nuclei for the exfoliation process.

Finally, we have shown that a sample of pure vermiculite, KL-2, does not exfoliate, neither thermally with flash-heating, nor chemically with $\mathrm{H}_{2} \mathrm{O}_{2}$ treatment. Judging from the results of $\mathrm{Cs}^{+}$ exchange this sample is the specimen closest in composition, structure and homogeneity to a true pure vermiculite, with no evidence for any chloritisation. As such when flash-heated, or treated with $\mathrm{H}_{2} \mathrm{O}_{2}$, the gas phases so produced may easily escape via unimpeded routes through the interlayer space; the result is that the sample does not exfoliate as there are no dead-end routes to block the escape of the gas phase. Paradoxically then, it would appear that a true pure vermiculite, in the mineralogical sense, will not show the property of exfoliation despite the fact that the mineralogical literature so often and readily cites exfoliation as a characteristic property of vermiculite.

\section{CONCLUSIONS}

The mechanism of thermal exfoliation is explained as a consequence of an intra-particle mosaic-like intergrowth of vermiculite, hydrobiotite and mica in 
most commercial 'Vermiculite' samples. The exfoliation of apparently pure true vermiculites that contain no potassium can also be explained by a mosaic structure, consisting of vermiculite and chlorite, achieved by nothing more than a switch in the nature of the interlayer from hydrated exchangeable cation interlayers in vermiculite to brucite-like interlayer hydroxide in chlorite. In both cases either fixed $\mathrm{K}^{+}$ions or fixed hydroxide interlayers act as barriers to gas escape because they occur in mosaiclike arrangements at a scale that is smaller than the particles. This mosaic arrangement is also the underlying factor and, thus, the common denominator which is responsible for chemical exfoliation when particles are treated with $\mathrm{H}_{2} \mathrm{O}_{2}$. In terms of its role in the exfoliation process, the mosaic-like arrangement provides a maze for escaping gas and consequently, the potential for dead ends, which act as pressure points. A build-up of pressure at such points that gives rise to forces in excess of interlayer bonding forces inevitably results in exfoliation. The model provides an explanation for the particle size dependence of the exfoliation process. It also explains why multiphase samples, especially if they have a high proportion of hydrobiotite, have the greatest capacity for exfoliation. The asymmetry of the exfoliated vermiform particles that first puzzled Groves (1939) is also explained since a contiguous layer traversing a particle may be a vermiculite layer in one place and a mica or a chlorite layer elsewhere. Specimens with characteristics that appear to indicate that they are pure vermiculite show the lowest capacities to exfoliate because they contain only minor amounts of intergrown chlorite meaning the extent of any mosaic structure is relatively low and there is consequently much less capacity for exfoliation to occur. More obviously poly-phase samples consisting of variously intergrown vermiculite, hydrobiotite and phlogopite show a much greater capacity to exfoliate determined by the extent, arrangement and scales at which their mosaic intergrowths occur.

\section{ACKNOWLEDGMENTS}

Thanks are due to Evelyne Delbos for part of Fig. 3, David Riley for the vermiculite photographs and the video, Ian Williamson for drafting Fig. 6, John Brown for arranging Figs 2, 3 and 4, and John Still for carrying out the EMPA analyses and supervision of SEM work at Aberdeen University. The manuscript also benefited from the reviews of Jeff Wilson, Richard April, Ismail Girgin, and Lisa Heller-Kallai, all of which are gratefully acknowledged.

\section{REFERENCES}

Bailey S.W. (1980) Comment: Summary of recommendations of AIPEA Nomenclature Committee. Clays and Clay Minerals, 28, 73-78.

Brindley G.W. \& Brown G. (1984) Crystal Structures of Clay Minerals and their X-Ray Identification. Mineralogical Society Monograph No. 5, London, 495 pp.

Brindley G.W., Zalba P.E. \& Bethke C.M. (1983) Hydrobiotite, a regular 1:1 interstratification of biotite and vermiculite layers. American Mineralogist, 68, 420-425.

Coleman J. N., Lotya M., O’Neill A., Bergin S.D., King P.J., Khan U., Young K., Gaucher A., De S., Smith R.J., Shvets I.V., Arora S.K., Stanton G., Kim H.Y., Lee K., Kim G.T., Duesberg G.S., Hallam T., Boland J.J., Wang J.J., Donegan J.F., Grunlan J.C., Moriarty G., Shmeliov A., Nicholls R.J., Perkins J.M., Grieveson E.M., Theuwissen K., McComb D.W., Nellist P.D. \& Nicolosi V. (2011) Two-dimensional nanosheets produced by liquid exfoliation of layered materials. Science, 331, 568-571.

Couderc P.\& Douillet Ph. (1973) Les vermiculites industrielles: exfoliation, caractéristiques minéralogiques et chimiques. Bulletin de la Société Française de Céramique, 99, 51-59.

De la Calle C. \& Suquet H. (1988) Vermiculite. Pp. 455-496 in: Hydrous Phyllosilicates (Exclusive of Micas) (S.W. Bailey, editor). Reviews in Mineralogy, 19, Mineralogical Society of America. Washington, D.C.

Douglas L.A. (1989) Vermiculites. Pp. 635-674 in: Minerals in Soil Environments, 2nd ed. (J.B. Dixon $\&$ S.B. Weed, editors). Soil Science Society of America, Book series no.1.

Drosdoff M. \& Miles E.F. (1938) Action of hydrogen peroxide on weathered mica. Soil Science, 46, 391-395.

Foster M.D. (1960) Interpretation of the composition of vermiculites and hydrobiotites. Clays and Clay Minerals, 10, 70-89.

Frank D. \& Edmond L. (2001) Feasibility for Identifying Mineralogical and Geochemical Traces for Vermiculite Ore Deposits. United States Environmental Protection Agency. Region 10, EPA 910-R-01-002.

Giese R.F. (1978) The electrostatic interlayer forces of layerstructure minerals. Clays and Clay Minerals, 26, $51-57$.

Groves R.C. (1939) Exfoliation of vermiculite by chemical means. Nature, 144, 154. 
Gruner J.W. (1934) The structure of vermiculites and their collapse by dehydration. American Mineralogist, 19, 557-575.

Guggenheim S., Adams J.M., Bain D.C., Bergaya F., Brigatti M.F., Drits V.A., Formoso M.L.L., Galán E., Kogure T. \& Stanjek H. (2006) Summary of recommendations of nomenclature committees relevant to clay mineralogy: report of the Association Internationale Pour l'Etule de Argiles (AIPEA) Nomenclature Committee for 2006. Clay Minerals, 41, 863-877.

Hall M.G. \& Lloyd G.E. (1981) The SEM examination of geological samples with a semiconductor backscattered electron detector. American Mineralogist, 66, 362-368.

Heller-Kallai L. (2006) Thermally modified clay minerals. Pp. 289-308 in: Developments in Clay Science, 1 (F. Bergaya, B.K.G. Theng \& G. Lagaly, editors). Handbook of Clay Science. Elsevier, Amsterdam.

Hillier S. (1999).Use of an air brush to spray dry samples for X-ray powder diffraction. Clay Minerals, 34, 127-135.

Hillier S. (2003) Quantitative analysis of clay and other minerals in sandstones by X-ray powder diffraction (XRPD). Pp. 213-251 in: Clay Mineral Cements in Sandstones (R.H. Worden \& S. Morad, editors). International Association of Sedimentologists, Special Publication, 34.

Hillier S. \& Clayton T. (1992) Cation exchange staining of clay minerals in thin section for electron microscopy. Clay Minerals, 27, 379-384.

Hindman J.R. (2006) Vermiculite. Pp. 1015-1026 in: Industrial Minerals and Rocks, Commodities, Markets and Uses, $7^{\text {th }}$ ed. (J.E. Kogel, N.C. Trivedi, M.J. Barker \& S. Krukowski, editors) Society of Mining, Metallurgy and Exploration.

Huo X. Wu L., Liao L., Xia Z. \& Wang L. (2012) The effect of interlayer cations on the expansion of vermiculite. Powder Technology, 224, 241-246.

Justo A., Maqueda C., Perez-Rodriguez J.L. \& Morillo E. (1989) Expansibility of some vermiculites. Applied Clay Science, 4, 509-519

Mackenzie R.C., editor (1957) The Differential Thermal Investigation of Clays. Mineralogical Society, London.

Marcos C. \& Rodríguez I. (2011) Expansibility of vermiculites irradiated with microwaves. Applied
Clay Science, 51, 33-37.

Midgley H.G. \& Midgley C.M. (1960) The mineralogy of some commercial vermiculites. Clay Minerals, 4 , $142-150$.

Muiambo H.F., Focke W.W., Atanasova M., Westhuizen I.V.D. \& Tiedt L.R. (2010) Thermal properties of sodium-exchanged Palabora vermiculite. Applied Clay Science, 50, 51-57.

Obut A. \& Girgin I. (2002) Hydrogen peroxide exfoliation of vermiculite and phlogopite. Minerals Engineering, 15, 683-687.

Obut A., Girgin I. \& Yorukoglu A. (2003) Microwave exfoliation of vermiculite and phlogopite. Clays and Clay Minerals, 51, 452-456.

Omotoso O., McCarty D.K., Hillier S. \& Kleeberg R. (2006) Some successful approaches to quantitative mineral analysis as revealed by the 3rd Reynolds Cup Contest. Clays and Clay Minerals, 54, $748-760$.

Paterson E. \& Swaffield R. (1987) Thermal analysis, Pp. 99-132 in: A Handbook of Determinative Methods in Clay Mineralogy (M.J. Wilson, editor). Chapman and Hall, New York.

Ruthruff R.F. (1941) Vermiculite and hydrobiotite. American Mineralogist, 26, 478-484.

Suvorov S.A. \& Skurikhin V.V. (2003) Vermiculite - a promising material for high-temperature heat insulators. Refractories and Industrial Ceramics, 44, 186-193.

Üçgül E. \& Girgin I. (2002) Chemical exfoliation characteristics of Karakoc phlogopite in hydrogen peroxide solution. Turkish Journal of Chemistry, 26, 431-439.

Walker G.F. (1951) Vermiculites and some related mixed-layer minerals. Pp. 199-223 in: X-ray Identification and Crystal Structures of Clay Minerals (G.W. Brindley, editor). Mineralogical Society, London.

Walker G.F. (1961) Vermiculites. Pp. 297-324 in: The X-ray Identification and Crystal Structures of Clay Minerals (G. Brown, editor). Mineralogical Society, London.

Weldon M.K., Marsico V.E., Chabal Y.J., Agarwal A., Eaglesham D.J., Sapjeta J., Brown W.L., Jacobson D.C, Caudano Y., Christman S.B. \& Chaban E.E. (1997) On the mechanism of the hydrogen-induced exfoliation of silicon. Journal of Vacuum Science \& Technology, 15, 1065-1073. 